\title{
(a) Towards a translational medical humanities: OPEN ACCESS introducing the cultural crossings of care
}

\author{
Eivind Engebretsen, ${ }^{1}$ Gina Fraas Henrichsen, ${ }^{2}$ John Ødemark ${ }^{3}$
}

${ }^{1}$ Institute of Health and Society, University of Oslo Faculty of Medicine, Oslo, Norway ${ }^{2}$ Centre for Health Science Education, University of Oslo Faculty of Medicine, Oslo, Norway

${ }^{3}$ Department of Cultural Studies and Oriental Languages, University of Oslo, Oslo, Norway

\section{Correspondence to}

Professor Eivind Engebretsen, Institute of Health and Society, University of Oslo Faculty of Medicine, 0372 Oslo, Norway; eivind.engebretsen@medisin. uio.no

Accepted 12 March 2020 Published Online First 27 April 2020
Check for updates

(C) Author(s) (or their employer(s)) 2020. Re-use permitted under CC BY-NC. No commercial re-use. See rights and permissions. Published by BMJ.

To cite: Engebretsen E, Fraas Henrichsen $G$, Ødemark J.

Med Humanit 2020;46:e2

\section{ABSTRACT}

In this introductory essay, we will present a translational medical humanities approach where the humanities are not only an auxiliary to medical science and practice, but also an interdisciplinary space where both medicine and the humanities mutually challenge and inform each other. First, we explore how medicine's attempt to tackle the nature-culture divide is emblematically expressed in the concept and practice of knowledge translation (hereinafter KT). Second, we compare and contrast KT as an epistemic ideology and a socio-medical practice, with concepts and practices of translation developed in the human sciences. In particular, we emphasise Derrida's understanding of translation as inherent in all meaning making, as a fundamentally textual process and as a process necessarily creating difference rather than semantic equivalence. Finally, we analyse a case from clinical medicine showing how a more refined notion of translation can enlighten the interaction between biomedical and cultural factors. Such a translational medical humanities approach also requires a rethinking of the concept of evidence in medicine.

\section{TOWARDS A TRANSLATIONAL MEDICAL HUMANITIES}

Medicine has always been a cultural enterprise. The Lancet Commission on Culture and Health from 2014 underscored this and provided new insights into the cultural dimensions of health. Most radically, it pointed out that 'the distinction between the objectivity of science and the subjectivity of culture is itself a social fact'. ${ }^{1}$ Still, by drawing attention to the 'effects of cultural systems' (our emphasis), ${ }^{1}$ and how these have an effect on health and medicine, the report also risks reinforcing the ontological divide between science and culture, rather than calling it into question. In line with the Lancet Commission, we maintain that there is a need for a fundamental questioning of the cultural distinction between the objectivity of science and the subjectivity of culture, the generality of the natural sciences and the singularity of the humanities. We believe, moreover, that the medical humanities should play a vital role in such a project. However, we also maintain that this endeavour calls for a rethinking of the medical humanities and health humanities ${ }^{2}$ as well as their grounding assumptions about what the humanities are, and how they could interact with medicine.

To explore such basic issues, we launched a call for a global think tank for the medical humanities in 2018. Our call, entitled 'The Cultural Crossings of Care', resulted in a conference in Oslo in October 2018. The articles collected in the present research forum are all contributions to the conference, and all tackle the radical dilemmas of the medical humanities. Moreover, a shared premise for this research forum is that the medical humanities should not only be construed as what we have called a 'soft' humanistic supplement to medical care, but also as constituent of, and hard factors behind, sickness and health. Thus, this research forum is a contribution to the development of the medical humanities, understood not only as a 'soft' humanistic supplement (as when reading poetry for the dying to soothe, but not to heal), but also, more radically, as a fundamental exploration of the cultural assumptions underlying biomedicine and healthcare. ${ }^{3}$ The contributors explore approaches to the medical humanities where the humanities are not only a supplement to medical science and practice, but also an interdisciplinary space where both medicine and the humanities challenge and inform each other across the mega-divide between the humanities and the natural sciences.

In the remainder of this introductory essay, we will use the so-called medical knowledge translation (hereinafter, KT) to explore such an interdisciplinary space, where both medicine and the humanities challenge and inform each other. This attempt to construct a new translational medical humanities is a work in progress-and it forms a part of our ongoing project, The Body in Translation: Historicising and Reinventing Medical Humanities and Knowledge Translation.

What is KT? WHO defined KT as " $\mathrm{t}$ ] he synthesis, exchange, and application of knowledge by relevant stakeholders to accelerate the benefits of global and local innovation in strengthening health systems and improving people's health'. In line with this broad definition, we will examine KT both as an epistemic ideology and as a socio-medical practice. KT is a good place to begin an exploration of the interdisciplinary space between medicine and the humanities. This is so because the abbreviation refers to a prominent practice within modern medicine, which in turn hinges on a paradoxical understanding of both the cultural context of health and the cultural assumptions underpinning biomedical research. On the one hand, KT reflects an increased concern with cultural contexts of medicine and healthcare by acknowledging that the transfer of knowledge from laboratory to clinic necessitates 'adaptation to local context'. But on the other hand, the concern with the cultural contexts of care is almost solely a concern with 'barriers' to the implementation of the 'truth' of biomedical science. Construed as an external context, culture is thus only relevant as an enemy which must be known to be conquered. 
On the contrary, we maintain that the medical humanities are a cross-disciplinary and cross-cultural space for translation and critical interrogation of both biomedicine (simplistic reductions of life to biology) and the humanities (simplistic reductions of suffering and health injustice to cultural relativism).

In the following, therefore, we will use KT to explore what we call 'translational medical humanities'. First, we demonstrate that medicine's attempt to tackle the nature-culture divide is emblematically expressed in KT. Second, we sketch how a more nuanced notion of KT in medicine can be constructed, by taking into account notions of translation developed in the social and human sciences. In particular, we focus on Derrida's understanding of translation as a supplement, that is as a textual process that always involves additions and adaptation to and of the original message. Finally, we will discuss a case from clinical medicine that demonstrates a more refined notion of translation in KT in clinical practice, and how the notion of the supplement reconfigures the notion of evidence.

\section{THE SCIENCE-CULTURE DIVIDE IN MEDICAL KT}

During the last 20 years, the use of metaphors of translation have become increasingly prominent, in order to map the relation between biomedical science as research, and its social use as care and cure. It has been observed that the term 'translation' was introduced into medicine in the late 1990 s as a reaction to the 'disconnection between the promise of basic science and the delivery of better health' (emphasis added). ${ }^{6}$ There was a widespread concern that 'despite increased efforts and investments into R\&D (research and development), the output of novel medicines has been declining dramatically'. ${ }^{7}$ Dominant research methods were questioned, and the need for more applied or 'translational' approaches was emphasised: 'Animal experiments, test tube analyses and early human trials do simply not reflect the patient situation well enough to reliably predict efficacy and safety of a novel compound or device'. ${ }^{8}$ Thus, new methods for clinical testing were required to bridge the gap and facilitate the transition from bench to bedside. Such methods were referred to as 'translations' and categorised into different steps and stages of a chain, as illustrated in figure 1.

This chain-or 'pipeline', another frequently used metaphor, is regularly defined in terms of two separate steps:

T1: Translation between basic science and development and testing of new therapies.

T2: Translation between recommendations gathered in medical guidelines and routine clinical practice. ${ }^{9}$

Although the metaphor of translation first emerged in medicine in the late 1990s, the idea of translating research into clinical application and bridging the space between scientific knowledge and social practice has a long pedigree. Genealogically speaking, the idea can be traced back to the Baconian understanding of science as an instrument of regaining 'dominion over creation'

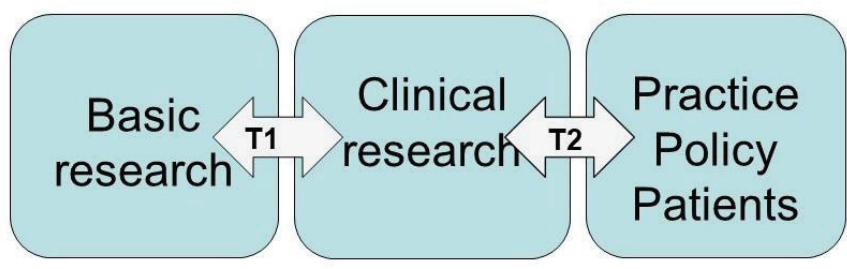

Figure 1 The so-called translational chain illustrating translation in two steps (T1 and T2) from basic research via clinical research and into practice, policy and patients. and thereby (in Francis Bacon's own wording) enlarging 'the bounds of human empire, to the effecting of all things possible'. ${ }^{10}$ A similar instrumental understanding of science was also central to Louis Pasteur's scientific ambition. Pasteur wrote that, 'to him who devotes his life to science, nothing can give more happiness than increasing the number of discoveries, but his cup of joy is full when the results of his studies immediately find practical applications'. ${ }^{11}$

What is actually new with the translational turn in medicine, however, is the recognition and acceptance of the challenge of translation. In Jane Maienschein's formulation, the novelty 'is an explicit recognition that translation is not easy, not inevitable'-and, as she added, is 'indeed, not happening. ${ }^{12}$ Now translation is no longer conceived as an integral and organic part of scientific progress itself as in the Baconian paradigm, and Pasteur's dream of a science that 'immediately finds practical applications' has been undermined. Translation is not an event that follows automatically with the production of new scientific knowledge and scientific progress. On the contrary, translation implies conscientious action and active manipulation, or else it is simply not happening.

To 'make translation happen', it is vital to reflect critically on how the 'message' is best accommodated to what we-in the language of translation studies (TS) — could call the various target texts and target cultures of KT. In other words, research must be made relevant and understandable to patients, clinicians, researchers and other target users. But the approach to culture in medical KT has largely been asymmetrical, the underlying assumption being that culture is a 'problem' relating solely to the target culture and target audience of medical knowledge (patient, practitioners), and not to the science itself, which is construed as transculturally valid and thus universally applicable. In KT ideology, then, clinicians and patients are broadly conceived as recipients of non-cultural scientific knowledge produced by biomedicine and other natural sciences. Thus, culture is understood as what we have called an 'epistemological lubricant ${ }^{\text {"13 }}$, to facilitate understanding and communication with clinicians and patients, but it is simultaneously excluded from the conceptualisation of science and scientific evidence.

This lack of reflection about culture in KT does not mean that medicine is not concerned with adaptation to local context. On the contrary, the attempt to 'individualise' the evidence is a frequently used mantra in KT. 'Context' in these approaches is not seen as the result of a 'thick description', however. ${ }^{14}$ Rather, the attempts to individualise and adapt the evidence and treatment contextually are paradoxically haunted by an understanding of evidence as universal and acontextual-and hence, non-cultural. Moreover, cultural factors in KT are generally associated with an exception, not the norm, and often with cultural 'otherness'. This seems to imply that culture is something you either possess or do not, or at least can have in different amounts; the more cultural the context, the more challenging the translational process is considered to be. Accordingly, several scholars have drawn attention to the particular challenges related to KT in explicit intercultural contexts. Santesso and Tugwell, for instance, underscored the importance of cultural factors when performing KT in 'developing countries', and they further claimed that 'success rests with tailoring KT strategies to the salient barriers and supports found within the setting. ${ }^{15}$ Furthermore, Summerfield argued that Western definitions and solutions to mental disorders cannot be routinely applied to people in 'developing countries'. ${ }^{16}$ Referencing Kleinman and Good, they asserted that 
Cultural worlds may differ so dramatically that translation of emotional terms means more than finding semantic equivalents. Describing how it feels to be aggrieved or melancholic in another society leads directly into an analysis of a radically different way of being a person. ${ }^{17}$

In the cited examples, 'culture' seems to be associated with particular cases relating to 'development countries' and 'mental disorders'. Culture is associated with cultural 'otherness', generally as the polar opposite to modernity ('developing countries'), and with particular 'soft' aspects of medical practice (mental health). Hence, the cultural approach to these medical contexts is still characterised by what Bauman and Briggs have called 'a poetics of otherness', describing people living before or outside scientific modernity, and ruled by individual or collective representations contrary to reason and the logos of biomedicine. ${ }^{18}$ Thus, in the KT approach we have dealt with here, the importance of cultural factors is not accounted for symmetrically (drawing on the notion of symmetry in Bloor and the sociology of science). A symmetrical account would admit that the place where science is produced, and not just the place of its reception, forms a part of culture, and that the translation between the laboratory and society is a translation between different cultural places—not between universally valid science and a local 'prejudice'.

\section{SUPPLEMENTING MEDICAL KT}

KT hinges on the mobilisation of a chain of inscriptions and textual genres, starting with research trials, followed by metaanalyses or systematic reviews (summarising the scientific state of the art), and culminating in clinical guidelines, which prescribe manners of intervention in concrete cases and contexts. It is assumed that all these textual genres transmit the evidence in increasingly condensed and vernacular forms, without threatening its universal and general character. Here, then, textual inscriptions are instruments mobilised to cross social spaces and to overcome cultural barriers. We see this clearly in an intriguing formulation in Straus et al's ${ }^{19}$ seminal textbook Knowledge Translation in Healthcare. In this textbook, the authors emphasised that a new 'culture' is a requirement for effective KT:

By actively engaging the targeted users in reviewing guideline recommendations and discussing any organisational changes required, an environment for communication and collaboration among health professionals, managers and decision makers is fostered. This culture (emphasis added) is crucial to overcome barriers to implementation. ${ }^{19}$

Thus, a certain 'culture' associated with 'an environment for communication and collaboration among health professionals, managers and decision making' is

1. a cultural tool for erasing local, cultural 'barriers' to the implementation of science, while

2. the relevant biomedical knowledge appears to be precultural and fully formed and inscribed in the guidelines-before the battle between 'good' and 'bad' culture.

The KT strategy for overcoming barriers is to disconnect the 'evidence' as a fully formed and autonomous text from its various contexts of production (for instance, clinical trials or guideline groups). The first step of the KT procedure is to identify and isolate the original scientific message, which is assumed to have universal validity, independent of the contexts and textual genres in which it is produced. This has regularly been referred to as the 'gold standard' of evidence. As such, it is similar to what Derrida refers to as a 'transcendental signified' because it transcends any particular expression of meaning, any given experiment, scientific genre or cultural context. The second step of KT is then to 'reactivate' the 'evidence' in a new referential space (the clinical encounter between specific patients and health providers) through the mobilisation of new textual genres (such as systematic reviews and clinical guideline recommendations), but without altering the original scientific message. As knowledge trickles down through the 'pipeline', it becomes more and more dissociated from the conditions of production from which it originates. Evidence now becomes 'stabilised' as the chains of inscription of which it forms a part, and through which it is produced, erased or black-boxed.

T1 research is typically developed by moving back and forth between laboratory work and notebooks, animal models and clinical settings, asking specific questions concerning the individuals included in the study: What are the characteristics of the individuals for whom the therapy worked for vs individuals who had no response?, Would the response have been better if the protocol for preparing the therapy was modified in some way? and so on. T2 research, on the other hand, raises questions that concern a general population. An intervention is tested on (ideally) a large population, with the so-called randomised-controlled trials (RCTs), which include the comparison of a treatment group and a control group. The movement from the specific to the general, facilitated by the RCTs, is also seen as a rise in quality of the evidence. This is reflected in the so-called evidence pyramid, which places early-stage laboratory translations on the bottom and latestage guideline translations on the top-the latter considered as the 'gold standard'.

The construal of translation in KT is analogous to a current deeply compromised literary view of translation. In the Western tradition, translation has generally been seen as a practice that aims in creating a semantic or pragmatic equivalence between an original 'source text' and a new 'target text ${ }^{\text {'20 }}$ - and as a process governed by the norm of fidelity to the source, and where the translator's work is 'invisible ${ }^{21}$ and merely 'ancillary'. ${ }^{22}$ This ties in to the romantic idea of preserving the literary masterpiece, emblematically formulated by Vladimir Nabokov-the person who desired to turn a literary masterpiece into another language and had only one duty to perform, and this is to reproduce with absolute exactitude the whole text, and nothing but the text. ${ }^{23}$

Indeed, in this view of translation, the translator will be doomed to treason, to be a traitor-of the original artistic genius-or, in $\mathrm{KT}$, of the scientific logos-insofar as the work of translation is productive. In contrast to this rejection of the productivity of translation, TS have emphasised that the original source text can never be fully recovered by the target text or culture. Translation always implies semantic shifts, and every translated text must be 'rewritten in domestic dialects and discourses, registers and styles' of the target language, and thus betray the original. ${ }^{24}$

The so-called actor network theory (ANT) and science and technology studies (STS) have similarly asserted the creativity of translation. Latour and other STS scholars claimed that the productivity of translation is the very condition for knowledge. Latour, moreover, saw a certain translation process as constitutive of modernity. On the one hand, modernity is based on a separation of nature and culture, science and the humanities. Culture and society are products of human construction, while nature exists in a realm beyond the sphere of human construction. Characteristics of 'modernity', however, are also the continuous processes of translation which link nature with culture and society. These translations, however, are also balanced by processes of 'purification' which re-establish the borders between nature and culture. Together, these interacting 
processes create 'hybrids' of nature and culture which make technological modernity work. ${ }^{25}$

Surely, KT can be described precisely as such a process of purification (in the context of the production of evidence) and hybridisation (the reinsertion into society of the new biomedical knowledge produced in the laboratory). In the case of text-based medical KT, however, it is interesting that Bauman and Briggs countered that Latour has 'left out two of the key constructs that make modernity work and make it precarious!', namely language and tradition. Lock's Treaties of Government serves as an example. Here Locke described three 'great provinces' that have to be kept separate to make objective claims about the world: things (nature), actions (society) and signs. ${ }^{26}$

Bauman and Briggs claimed that language and semiotics play 'a secondary, derivative role in articulating the relationship between society and nature' in Latour. ${ }^{27}$ This is paradoxical, first because of Latour's attention, especially in his early work, to the role of language, texts and inscriptions in the production of scientific fact. ${ }^{28}$ Second, it is also paradoxical because salient terms in the 'new' vocabulary of ANT and STS were actually translated from semiotics and narratology; the notion of the 'actant' is the most salient case in point. Mol asserted that ANT represents an expansion of linguistic structuralism to other network relations: 'In ANT this semiotic understanding of relatedness has shifted from language to the rest of reality'. ${ }^{29}$ Even so, texts and linguistics often seem to have been lost somewhere in this translational 'shift'. In line with Bauman and Briggs, we maintain that Latour's emphasis on the non-immediacy and mediated character of any knowledge or meaning of any entity-both human and non-human-should be supplemented by an increased awareness of the productivity of texts in translational processes such as KT.

\section{TEXTUAL PRODUCTIVITY IN MEDICAL TRANSLATION}

Derrida regarded translation as an integral part of all textual production. According to him, translation is not an accidental event that can happen to a text in empirical cases where the text is turned into another (target) language. On the contrary, translation and semantic productivity are essential parts of the text's mode of being in the world. The struggle to create meaning in the text, interpret it 'correctly', is simultaneous with the birth of the text.

By emphasising the supplementary character of translation, Derrida played on the double meaning of the word supplement, as both adding on to the original and compensating for a lack in the original. ${ }^{30}$ The supplement is at the same time an addition from the outside to something natural and original and a compensation for an insufficiency inscribed within the natural origin. Hence, the supplement is both cultural and natural, both external and internal to the phenomenon it supplements.

Derrida's deconstructive readings are often concerned with the supplementary status of concepts or phenomena. His most prominent example is writing that 'is the supplement par excellence since it proposes itself as the supplement of the supplement, sign of a sign, taking the place of a speech already significant'. ${ }^{31}$ In his critical reading of Walter Benjamin, Derrida also used translation as an example of a supplement in a similar sense. In fact, Benjamin himself used this very word, but, according to Derrida, in a more narrow sense. According to Benjamin, the translation supplements the original by enriching the original text; 'it envelops its content like a royal robe with ample folds'. ${ }^{32}$ However, Benjamin's metaphor also implies that the original message remains intact. Hence, Benjamin did not take into account the second aspect of the supplement, that the original text is not complete but 'fulfilled' through interpretation.

Such an idea of translation as supplement-conceived in this double sense-has potentially broad implications for KT:

1. The translation aspect of KT does not only duplicate and disseminate the original knowledge, but it also completes the original 'scientific text' by fulfilling it with a possible interpretation in a particular context. Indeed, this supplementary logic is implicit in existing KT models. While KT models presuppose that the principal duty of adequate KT is to implement the original scientific message in new social contexts and textual forms without altering its content, the same models, paradoxically, also state that it is through translational modifications and adaption to new audiences, that is, through synthesis and development of guideline recommendations, that the message becomes scientifically trustworthy. However, existing KT models fail to draw the necessary consequences from this paradox. A cultural supplement in terms of interpretation and adaptation to new genres and audiences is inherent in the production of scientific facts. KT could become more effective-not less-if such shifts were defined as a creative potential rather than as a mere 'barrier'.

2. The necessity of interpreting and translating texts-the fact that texts do not speak for themselves, but are constantly objects of interpretation, and are scrutinised for their true meaning - 'always already' characterises the original text to be translated. Such a broad conceptualisation of translation implies a fundamental criticism of the translation concept inherent in KT. As argued, KT is based on an idea of translation as a two-step procedure starting with (1) the dissociation of the scientific signified from the text, followed by (2) the reincorporation of this transcendental scientific signified into a new text. Derrida challenged this notion by showing how translation is always already operating within the original scientific message. In other words, knowledge is always already part of a textual and intertextual interplay. To translate knowledge inevitably implies engaging with this textual production through constant comparison and contrasting of various textual expressions. Knowledge has no transcendent status, but it is an immanent and integral part of a textual productivity. Thus, KT cannot be accomplished through detextualisation and retextualisation of the scientific message. We maintain that medical translation should rather be thought in terms of a difference between cultural and textual spaces than as an application of one onto another. It is by comparing and contrasting various texts across the translational chain, such as patients' narratives, clinical trials, case studies, guidelines and so on; and by doing so, producing a new text. This is how KT comes about. We claim that KT has to be found in the interval between texts, and not in the search for equivalence.

In the last section, we will illustrate these theoretical notions by analysing a case study from clinical medicine, more precisely an auto-ethnographic analysis of her own experiences as a patient, written by Trisha Greenhalgh, a medical doctor and a scholar in health sciences. Greenhalgh pointed out the problematic implications of understanding KT in terms of application based on equivalence.

\section{KT AND THE SINGULARITY OF EVIDENCE}

Professor Greenhalgh was victim of a serious bike accident and had to undergo surgery due to fractures in both her arms and neck. After surgery, her doctor advised her not to take 
non-steroidal anti-inflammatory drugs (NSAIDs) (ibuprofen, aspirin, etc) for the pain for a whole month, claiming that there was 'some evidence for delayed healing of bone repairs, and risk of bleeding is higher in the post-op period'. ${ }^{33}$ The doctor's evidence-informed advice was the result of a standard KT procedure in the sense that it was based on the review and translation of various research studies into a univocal practical recommendation. However, when retracing the translational chain underpinning the doctor's claim, Greenhalgh discovered that the evidence warranting it was far from univocal. The doctor's advice actually black-boxed a whole series of interpretations and cultural transformations leading to the claim. First, the doctor's advice concealed differences between various scientific genres. Greenhalgh found at least three different types of studies underpinning the claim:

1. Animal studies of rats with induced fractures, in which one group of animals was given NSAIDs and one was not. These studies indicated that the animals that received NSAIDs showed slower healing.

2. Retrospective case-control studies of patients with delayed healing who were likely to have taken NSAIDs.

3. RCTs showing that postsurgical patients (independent of disease and surgical intervention) had higher incidence of bleeding.

Second, these different scientific genres also reflected very different designs and set-ups. (1) Animals with induced fractures (the researchers had broken their legs as part of the experiment), (2) humans with slow healing of various fractures who-thinking back-might have taken NSAIDs and (3) a randomisation of groups of patients with completely different conditions where those given a non-steroid showed increased risk of bleeding.

Third, all these studies reflected cultures that were very different from the setting in which Greenhalgh's incident occurred. Greenhalgh was an ex-elite athlete, and he had years of experience with moderate doses of NSAIDs with no adverse effects. As an athlete, she had several experiences with injuries and fractures which were treated with NSAIDs and healed very well. When translating the evidence of her case, none of these singularities were taken into account.

The point here is not to argue that the doctor's conclusion was wrong or to make a general point about NSAIDs in postoperative fracture treatment. Rather our point is that the doctor's conclusion is based on an inadequate understanding of KT. The conclusion was drawn based on an assumption of equivalence between the contextually purged and generalised evidence taken from biomedical research and the patient's singular case. The case demonstrates that evidence cannot be detached from its various cultural and textual forms of production. Cultural and textual processes are not only soft supplements, but also hard factors in the translation and application of knowledge. It is only by emphasising (not erasing) the differences between genres, designs and cultures involved that KT can come about. Hence, medical KT is a scientific and a cultural practice on equal terms. A decision in Greenhalgh's case could only be made through careful analysis of what makes her case singular in relation to other contexts of evidence.

The lesson from this case is that evidence should be seen as a system, or a net of traces-in Latour's idiom, it has a network character-converging in singular case histories (like Greenhalgh's). ${ }^{34}$ However, universal categories are also essential in evidence-based decisions, and the notion of the singular is already a general notion of a general category of singularities opposed to the general or nomothetic. ${ }^{35}$ Knowledge about generalised pathologies is needed both to identify the singular case as singular (ie, as distinct from a general category) and to create a linguistic, co-created space for transactions and translations between patients and medical specialists. It is only by knowing how a population generally reacts to an intervention or treatment that it is possible to identify how this patient reacts differently or specifically, given his or her particular illness or healing history.

Echoing Homi Bhabha, one might perhaps claim that KT represents a 'third space', an in-betweenness that illuminates the differences between research and practice. ${ }^{36}$ Here ' $[t]$ he translator is no longer a mediator between two different poles, but her/ his activities are inscribed in cultural overlappings which imply difference. ${ }^{37}$ Knowledge can only translate through the production and reproduction of difference-through acts of differing (what Derrida called différance), which are also the condition of possibility for any knowledge or meaning. This différance will undermine any attempt to detextualise and name the evidence-as in the case of Greenhalgh's doctor. Medical KT cannot escape textual and cultural productivity. KT cannot be performed by a 'translational medicine' approach, which considers translation as an unproductive, purely technical and communicative process, with the sole aim of carrying the scientific message across the gap between bench and bedside. It is this notion of the text's need for supplementary interpretations in an ever-expanding range of new contexts marked by biocultural singularity we want to claim as the precondition for a translational medical humanities.

\section{TRANSLATIONAL MEDICAL HUMANITIES: A WORK IN PROGRESS}

The case examined earlier demonstrates the need for a translational medical humanities approach which considers cultural and scientific factors as intermingled in the production and transmission of medical knowledge. The humanities, however, cannot offer a lost 'wholeness' (as 'romantic' or holistic notions of medical humanities often assume they can) to a 'fallen' biomedicine. It follows from this that we should not consider the humanities as a critical and potentially liberating perspective which can be applied to medicine to 'mend' a broken thing in need of repair. Medical humanities should rather be seen as a crossdisciplinary and cross-cultural space for a bidirectional critical interrogation of both biomedicine (simplistic reductions of life to biology) and the humanities (simplistic reductions of suffering and health injustice to cultural relativism). On the one hand, this implies breaking with the culture-nature dichotomy and considering both the humanities and medicine as biocultural practices. On the other hand, it also implies understanding that boundary work requires boundaries, and that incommensurability between various partial disciplinary perspectives can—and will—emerge. Such a bidirectional approach to the medical humanities suggests that the humanities should not be considered as a kind of metaknowledge, representing a critical or communicative 'add-on' to the biomedical knowledge that is believed to concern and intervene in health issues more directly. The humanities address hard factors behind sickness and healing. This does not mean that a biomedical approach can be reduced to social or cultural factors, considering culture as the real and 'hidden' reason behind the 'construction' of biomedical facts. However, cultural aspects of health and illness can never be clearly separated from, and are always intimately intermingled with, their biological 'other'. It is sufficient to think of how human living interferes with biological life by provoking resistance against antibiotics or by influencing 
the spread of malaria and other mosquito-borne diseases through the growth of human settlements.

Moreover, a bidirectional interrogation of biomedicine and the humanities implies considering medicine as a possible corrective to the humanities. In fact, medicine can guard against simple relativism in culture studies and serve as a reminder to the material conditions on which cultural interpretations are based. What we should maintain from the outset, however, is that biomedicine is not only culturally produced, but that the humanities are also materially productive; they create bodies and physical conditions. All contributors to this research forum explore approaches to the medical humanities, where the humanities are not only supplements to medical science and practice, but also an interdisciplinary space where both medicine and the humanities mutually challenge and inform each other.

\section{Twitter Eivind Engebretsen @eivinden}

Acknowledgements This article was written as part of the international research programme on 'The Body in Translation: Historicising and Reinventing Medical Humanities and Knowledge Translation' at the Centre for Advanced Study at the Norwegian Academy of Science and Letters in Oslo during the academic year 2019/2020

Contributors EE and JØ conceptualised the paper. EE wrote first draft. JØ and GFH revised the paper. All authors have accepted final version.

Funding The authors have not declared a specific grant for this research from any funding agency in the public, commercial or not-for-profit sectors.

Competing interests None declared.

Patient and public involvement Patients and/or the public were not involved in the design, or conduct, or reporting, or dissemination plans of this research.

Patient consent for publication Not required.

Provenance and peer review Not commissioned; externally peer reviewed.

Data availability statement No data. Theoretical paper.

Open access This is an open access article distributed in accordance with the Creative Commons Attribution Non Commercial (CC BY-NC 4.0) license, which permits others to distribute, remix, adapt, build upon this work non-commercially, and license their derivative works on different terms, provided the original work is properly cited, appropriate credit is given, any changes made indicated, and the use is non-commercial. See: http://creativecommons.org/licenses/by-nc/4.0/.

\section{NOTES}

1. A. David Napier et al. (2014), "Culture and Health," Lancet 384, no. 9954 (October 2014): 1607. https://doi.org/10.1016/S0140-6736(14)61603-2

2. Sarah Atkinson et al. (2015), "'The Medical' and 'Health' in a Critical Medical Humanities," Journal of Medical Humanities 36, no.1: 71-81. https://doi.org/10.1007/ s10912-014-9314-4

3. Julia Kristeva et al. (2018), "Cultural Crossings of Care: An Appeal to the Medical Humanities," Medical Humanities 44, no. 1: 55-58. http://dx.doi.org/10.1136/ medhum-2017-011263

4. https://cas.oslo.no/research-groups/the-body-in-translation-historicising-andreinventing-medical-humanities-and-knowledge-translation-article2753-827.html

5. World Health Organization, "Ageing and Life Course: Knowledge Translation." Accessed 7 June 2019. https://www.who.int/ageing/projects/knowledge_translation/ en/

6. Nancy S Sung et al. (2003)., "Central Challenges Facing the National Clinical Research Enterprise," JAMA 289, no. 10 (March 2003): 1279. doi:10.1001/jama.289.10.1278

7. Martin Wehling (2008), "Translational Medicine: Science or Wishful Thinking?" Journal of Translational Medicine 6, no. 31 (June 2008). doi:10.1186/1479-5876-6-31

8. Ibid.

9. Martin Wehling (2015), Principles of Translational Science in Medicine: From Bench to Bedside, 2nd ed. (Elsevier Science), 3.

10. Francis Bacon (1900), New Atlantis (University Press), 1627.

11. René. J Dubos (1950) Pasteur: Free Lance of Science (Little, Brown and Company), 41.

12. Jane Maienschein, Mary Sunderland, and A Rachel (2008)., "The Ethos and Ethics of Translational Research," The American Journal of Bioethics 8, no. 3: 44. https://doi-org. ezproxy.uio.no/10.1080/15265160802109314

13. Kristeva et al., "Cultural Crossings."
14. Clifford Geertz (1973), The Interpretation of Cultures (New York: Basic Books, 1973).

15. Nancy Santesso and Peter Tugwell (2006), "Knowledge Translation in Developing Countries," Journal of Continuing Education in the Health Professions 26, no.1: 87. doi:10.1002/chp.55

16. Derek Summerfield (2008), "How Scientifically Valid is the Knowledge Base of Global Mental Health?" BMJ 336.7651: 992-994. Accessed 19 January 2020. www.jstor.org/ stable/20509650

17. Arthur Kleinman and Byron Good (1985), Culture and Depression: Studies in the Anthropology and Cross-cultural Psychiatry of Affect and Disorder (Los Angeles: University of California Press), quoted in David Summerfield, "How Scientifically ...": 993.

18. Richard Bauman and Charles Briggs (2003), Voices of Modernity. Language Ideologies and the Politics of Inequality (Cambridge: Cambridge University Press).

19. Sharon E Straus, Jacqueline Tetroe, and Ian D Graham (2009), Knowledge Translation in Health Care: Moving from Evidence to Practice (John Wiley \& Sons), 80.

20. Eugene A Nida and Charles R. Taber (1969), The Theory and Practice of Translation, With Special Reference to Bible Translating (Leiden: Brill).

21. Lawrence Venuti (1995), The Translator's Invisibility (London: Routledge).

22. Antoine Berman (1984), Lépreuve de l'étranger: Culture et traduction dans I'Allemagne romantique (Paris: Gallimard).

23. Vladmir Nabokov (2012), "Problems of translation: Onegin in English (1955)," in The Translation Studies Reader, ed. Lawrence Venuti (London and New York: Routledge): 119.

24. Venuti Lawrence (2009), "Translation, Community, Utopia," in The Princeton Sourcebook in Comparative Literature, eds. David Damrosch, Natalie Melas and Mbongiseni Buthelezi (Princeton: Princeton University Press), 362.

25. Bruno Latour (1993), We Have Never Been Modern (New York: Harvester Wheatsheaf). 26. Bauman \& Briggs.Voices of Modernity, 5-8.

27. Ibid., 8.

28. Bruno Latour and Steve Woolgar (1986), Laboratory Life: The Construction of Scientific Facts (Princeton, NJ: Princeton University Press).

29. Annemarie Mol (2002), The Body Multiple (Duke University Press), 257.

30. Jacques Derrida (1997), Of Grammatology (Baltimore: John Hopkins University Press).

31. Ibid., 281.

32. Walter Benjamin, "The Task of the Translator," in Walter Benjamin: Selected Writings, Volume 1: 1913-1926, eds. Marcus Bullock and Michael W. Jennings (Harvard: Belknap Press of Harvard University Press, 1996), 253-263.

33. Trish Greenhalgh (2015), "Real vs Rubbish EBM: What is the state of Evidence-Based Medicine, and is it Broken?" Evidence Live, April 13-14 (2015). Accessed 1 April 2019. https://youtu.be/qYvdhA697jl

34. Bruno Latour (1996), "On Actor-Network Theory: A Few Clarifications," Soziale Welt 47, no. 4: 369-381.

35. Kristeva et al., Cultural Crossings of Care.

36. Homi Bhabha (2004), The Location of Culture (London and New York: Routledge).

37. Michaela Wolf (2000), "The Third Space in Postcolonial Representation," in Changing the Terms: Translating in the Postcolonial Era, eds. Simon Sherry and St-Pierre Paul (Ottawa: University of Ottawa Press), 127-146. Accessed 20 January 2020. www.jstor. org/stable/j.ctt1ckpcz7.10

\section{BIBLIOGRAPHY}

Atkinson, Sarah, Bethan Evans, Angela Woods, and Robin Kearns. "'The medical' and 'health' in a critical medical humanities." Journal of Medical Humanities 36, no. 1 (2015): 71-81.

Bacon, Francis. New Atlantis: University Press, 1900.

Bauman, Richard, and Charles Briggs. "Voices of modernity." Language Ideologies and the Politics of Inequality. Cambridge: Cambridge University Press, 2003.

Berman, Antoine. L'épreuve de l'étranger: Culture et traduction dans I'Allemagne romantique. Paris: Gallimard, 1984.

Bhabha, Homi. The Location of Culture. London and New York: Routledge, 2004. Derrida, Jacques. Of Grammatology. Baltimore: John Hopkins University Press, 1997. . Psyche: Inventions of the Other, vol. 1: Stanford University Press, 2007.

Dubos, René. J. Pasteur: Free Lance of Science: Little, Brown and Company, 1950.

Geertz, Clifford. The Interpretation of Cultures. New York: Basic Books, 1973.

Greenhalgh, Trish. "Real vs rubbish EBM: what is the state of evidence-based medicine, and is it broken?" Evidence Live (2015) Accessed April 1, 2019. https://youtu.be/ qYvdhA697jl

Greenhalgh, Trisha, and Sietse Wieringa. "Is it time to drop the 'knowledge translation' metaphor? A critical literature review." Journal of the Royal Society of Medicine 104, no. 12 (2011): 501-9.

We Have Never Been Modern. New York: Harvester Wheatsheaf, 1993.

Latour, Bruno. "On actor-network theory: a few clarifications." Soziale Welt 47, no. no. 4 (1996): 369-81. 


\section{Original research}

Kleinman, Arthur, and Byron Good. Culture and Depression: Studies in the Anthropology and Cross-Cultural Psychiatry of Affect and Disorder. Los Angeles: University of California Press, 1985.

Kristeva, Julia, Marie Rose Moro, John Ødemark, and Eivind Engebretsen. "Cultura crossings of care: an appeal to the medical humanities." Medical Humanities 44, no. 1 (2018): 55-8.

Latour, Bruno, and Steve Woolgar. Laboratory Life: The Construction of Scientific Facts. Princeton, N.J: Princeton University Press, 1986.

Lawrence, Venuti. "Translation, Community, Utopia." In The Princeton Sourcebook in Comparative Literature, edited by David Damrosch, Natalie Melas, and Mbongiseni Buthelezi, 358-79. Princeton UP: Princeton, 2009.

Maienschein, Jane, Mary Sunderland, and A Rachel. "Ankeny and Jason Scott Robert. "The Ethos and Ethics of Translational Research." The American Journal of Bioethics 8, no. no. 3 (2008): 43-51.

$$
\text { . The Body Multiple: Duke University Press, } 2002 .
$$

Mol, Annemarie. The Logic of Care: Health and the Problem of Patient Choice: Routledge, 2008

Nabokov, Vladmir. "Problems of translation: Onegin in English." In The Translation Studies Reader, edited by Lawrence Venuti. London and New York: Routledge, 2012.

Napier, A. David, Clyde Ancarno, Beverley Butler, Joseph Calabrese, Angel Chater, Helen Chatterjee, and Francois Guesnet., et al. "The Lancet Commission on culture and health." Lancet 384, no. no. 9954 (2014).
Nida, Eugene A, and Charles R. Taber. The Theory and Practice of Translation, With Special Reference to Bible Translating. Brill: Leiden, 1969.

Santesso, Nancy, and Peter Tugwell. "Knowledge translation in developing countries." Journal of Continuing Education in the Health Professions 26, no. 1 (2006): 87-96.

SharonE Straus, Jacqueline Tetroe, and IanD Graham. eds. Knowledge Translation in Health Care: Moving from Evidence to Practice: John Wiley \& Sons, 2009.

Summerfield, Derek. "How scientifically valid is the knowledge base of global mental health?" BMJ 336, no. 7651 (2008): 992-4.

Sung, Nancy S, William F Crowley, Myron Genel, Patricia Salber, Lewis Sandy, Louis M Sherwood, Stephen B Johnson., et al. "Central challenges facing the National clinical research enterprise." JAMA 289, no. 10 (2003): 1278-87.

Venuti, Lawrence. The Translator's Invisibility. London: Routledge, 1995.

Wehling, Martin. "Translational medicine: science or wishful thinking?" Journal of Translational Medicine 6, no. no. 31 (2008), 31.

Principles of Translational Science in Medicine: from Bench to Bedside, 2nd edn ed: Elsevier Science, 2015.

Wolf, Michaela. "The Third Space in Postcolonial Representation." In Changing the Terms: Translating in the Postcolonial Era, edited by Simon Sherry, and St-Pierre Paul, 127-46. Ottawa: University of Ottawa Press, 2000. www.jstor.org/stable/j. ctt1ckpcz7.10

World Health Organization. "Ageing and Life Course: Knowledge Translation." . https:/ www.who.int/ageing/projects/knowledge_translation/en/. Accessed June 7, 2019. 